\title{
Digitalização, flexibilidade e reordenação dos processos jornalísticos
}

\author{
César Ricardo Siqueira Bolaño ${ }^{1}$ \\ UFS/UnB \\ Valério Cruz Brittos² \\ Unisinos
}

\begin{abstract}
Resumo: $O$ objetivo deste texto é fornecer alguns elementos para a sistematização de um modelo teórico e analítico para o estudo do jornalismo online, considerando-o como um dos vetores da convergência audiovisualinformática-telecomunicações, que se realiza na internet, elemento chave do processo de digitalização geral do mundo, fruto da mudança estrutural por que passa o capitalismo desde o início da crise dos anos 70 do século passado. Para isso, realiza-se uma abordagem a partir da Economia Política da Comunicação, discutindo a reorganização do mundo jornalístico, tendo em vista a passagem para o patamar digital.
\end{abstract}

Palavras chave: Economia política da comunicação; jornalismo digital; trabalho cultural.

1 Professor da Universidade Federal de Sergipe (UFS) e do Programa de Pós-Graduação em Ciências da Comunicação da Universidade de Brasília (UnB). Jornalista pela Universidade de São Paulo (USP) e doutor em Economia pela Universidade Estadual de Campinas (Unicamp). Bolsista de produtividade (nível 1) do Conselho Nacional de Desenvolvimento Científico e Tecnológico (CNPq).

2 Professor no Programa de Pós-Graduação em Ciências da Comunicação da Universidade do Vale do Rio dos Sinos (UNISINOS) e doutor em Comunicação e Cultura Contemporâneas pela Faculdade de Comunicação (FACOM) da Universidade Federal da Bahia (UFBA). Presidente do Capítulo Brasil da União Latina de Economia Política da Informação, da Comunicação e da Cultura (ULEPICC-Brasil). 
Resumen: El objetivo de este texto es ofrecer algunos elementos para la sistematización de un modelo teórico y analítico para el estudio del periodismo en linea, considerado como uno de los vectores de la convergéncia audiovisual-informática-telecomunicaciones, que se realiza en la internet, elemento clave del proceso de digitalización general del mundo, fruto de la reestructuración por que pasa el capitalismo desde el principio de la crisis de los años 7o's del siglo pasado. Para eso, se utiliza el aporte de la Economía Política de la Comunicación, discutiendo la reorganización del mundo periodístico, teniendo en cuenta el paso al paradigma digital.

Palabras clave: Economía política de la comuncicación; periodismo digital; trabajo cultural.

Résumé: Ce texte a pour objectif presenter quelques elements pour une sistematisation du modele théorique et analitique pour l'étude du journalisme en ligne, consideré comme un des vecteurs de la convergeance audiovisuelinformatique-télécommunications, qui se realize en internet, element clef du processus de digitalisation général du monde, consequence de la restructuration du capitalisme qui se deroule depuis le debout de la crise des années 70 du siècle anterieur. On utilize l'approche de l'Economie Politique de la Communication, en discutant la reorganisation du monde journalisttique, prenant en compte le passage vers le paradigme digitale.

Mots clefs: Economie Politique de la Communication; journalisme digital; travail culturel

Abstract: The purpose of this paper is to offer some elements in order to sistematise a theoretical and analytical approach to the study of on line journalism, considered as one of the vectors of the audiovisual-informaticstelecommunications convergeance. Internet produce this convergeance, a key element of the worldwide general digitalization process, consequence of the capitalist restructuration that begins with the crisis of the 7o's of last century. Our approach is the Political Economy of Communication, a fundamental point to understand the journalistic field restructuration, considering the changes that conform the digital paradigm.

Key words: Political economy of communication; digital journalism; cultural work. 


\section{Introdução}

Com a digitalização, os processos midiáticos, em geral, são alterados, tanto no que se refere à organização dos mercados culturais, quanto às rotinas empresariais, à criação, produção e disponibilização de conteúdos, quanto à relação com os consumidores. Ao lado do potencial que tem o desenvolvimento tecnológico, de criação de novas estruturas, mercados, indústrias, trajetórias tecnológicas (concorrência intermídia), há uma série de decorrências que devem ser analisadas, notadamente envolvendo o ingresso de novos agentes relevantes, aliados ou não a outros, não hegemônicos, já presentes em um determinado mercado ou setor já existente, com potencial de desestabilização (concorrência intramídia).

A convergência tecnológica estimula fusões e acordos entre corporações, gerando novos negócios e, inclusive, provocando a necessidade de convivência entre modelos de gestão. Enquanto grupos empresariais buscam potencializar seus arquivos, digitalizando-os, atores não-hegemônicos tentam, através da digitalização, alterar a arena midiática. Para ambos, o conteúdo jornalístico funciona como instrumento importante para a atração e fidelização do público.

Progressivamente, a partir de 1995, quando se abriu o período de explosão da internet comercial, com a linguagem HTML (Hypertext Markup Language) servindo de base para a maioria dos sítios, a notícia, segmentada ou generalista, da própria organização, de um dado setor, de uma cidade, ou de tudo um pouco, tem sido um recurso importante para conquistar acessos regulares, o que pode redundar em verbas de publicidade, cada vez mais presentes na rede, perante o aperfeiçoamento dos processos de mensuração da audiência.

Isso é imprescindível para o mercado publicitário, que busca o maior retorno a partir do menor custo por mil possível, premido pelos enxugamentos generalizados de verbas, num momento, como o atual, de reestruturação empresarial generalizada. O controle do número de acessos e outros dados facilmente disponíveis para os veículos digitais aumentam sua credibilidade junto aos clientes. A publicidade online permite 
inclusive a condução do internauta à própria página do anunciante, além de conhecer o seu tempo de exposição à peça.

O jornalismo é um produto histórico, resultado de influências econômicas, políticas, tecnológicas e sociais. Sendo assim, tem sido alterado através do tempo, como produto transversal, adequável às várias mídias, o que o fez passar do impresso para o rádio, depois para a TV e agora para a internet, não esquecendo o jornalismo cinematográfico, para não falar em todo o cinema documentário. A mídia impressa, especificamente, passou, ao longo do tempo, de eminentemente política a empresarial, centrando-se mais na cobertura dos fatos cotidianos e menos interessada no chamado artigo de fundo, voltando-se para públicos mais focados.

Mais recentemente, as empresas jornalísticas buscam formas de rentabilização heterodoxas, centradas na distribuição de outras mercadorias, como revistas, vídeos, livros, CDs, DVDs, coleções de selos, brinquedos ou moedas. A situação pode parecer esdrúxula, mas encontra uma explicação simples e clara na teoria do ciclo de vida dos produtos, aplicada aos bens culturais (SALAÜN, 1989): a imprensa é uma indústria velha, em fase de declínio, dominada pela distribuição, que se vale do controle que tem sobre as redes capilarizadas de venda direta ao público para comportar-se muitas vezes mais como capital comercial do que industrial.

\section{Economia política e jornalismo on-line}

Outro fenômeno afeta também o setor: a sua passagem para o patamar digital. A informatização da imprensa brasileira, por exemplo, teve seu maior impulso nos anos 80 do século XX, espalhando-se para quase todos os veículos na década seguinte. O primeiro jornal brasileiro a informatizar suas redações, no começo daquele decênio, foi a Folha de $S$. Paulo. Em todo o mundo, a chegada dos computadores à mídia impressa implicou logo em reduções de quadros funcionais, levando a demissões, primeiramente de profissionais como montadores e revisores.

Além da informatização da redação e dos processos produtivos em geral do jornalismo impresso, radialístico e televisivo, os principais veículos desses meios incorporaram a internet como espaço de monitoramento e mesmo de visibilidade de suas 
organizações e estratégias, contando com sítios próprios, onde não só reproduzem parte dos materiais já disponibilizados em seus canais tradicionais, mas também ofertam conteúdos diferenciados, sobre a organização, suas atrações e também gerais, em certos casos. No caso dos jornais, a questão é mais complexa e a mudança de maior monta, ainda que não necessariamente o on-line substitua o impresso, embora sempre o reposicione, já que as duas mídias passam a conviver.

Mais do que a teoria do ciclo de vida, vale aqui a das trajetórias tecnológicas, aplicada às indústrias culturais. Há muita versão na internet de jornais impressos, mas, ao lado disso, o jornalismo on-line, como conteúdo capaz de exercer forte atrativo para o público, também tem sido incorporado por um conjunto de sítios e portais com origem não jornalística. Deve-se acrescentar ainda o fenômeno dos blogs e de um conjunto de periódicos que sobrevivem exclusivamente na internet, via de regra voltados a tópicos de interesse específico. Tudo isso torna bastante complexa a tarefa de traçar classificações e periodizações, questão que é retomada posteriormente neste artigo.

Não só os resultados, mas os padrões de produção cultural são afetados pela nova dinâmica da produção jornalística, requerendo, de um mesmo profissional, habilidades para manipular formatos diferentes no tratamento de uma temática. Relativamente ao jornalismo, a passagem para o online também acarreta mudanças, representando a digitalização a convergência de vários formatos (vídeo, áudio, texto) numa solução tecnológica para a distribuição de um produto único, o que requer capacidade ampliada para processar todos esses materiais.

Flexibilidade é a palavra de ordem no mundo dos negócios de hoje. O jornalismo digital amplia "o rumo atual da flexibilização em geral, que, espraiandando-se sobre todos os setores da vida social, incluindo sociabilidade, política e emprego, chega à produção e consumo comunicacional, imbricando-se tecnologias, formas organizacionais, meios e formas de recepção" (BRITTOOS, 2006).

O jornalista on-line, por exemplo, pode ser um profissional capaz de transportar as informações de outras mídias para a web, mas também alguém que simultaneamente atue 
em vários meios, uma característica solicitada pelos conglomerados com negócios em vários setores culturais. Assim:

Há uma forte flexibilização do trabalho e uma tendência ao apagamento das fronteiras entre as especialidades jornalísticas, com o repórter exercendo, por exemplo, a função de fotógrafo. As atividades próprias do jornalista vão-se, assim, de um modo geral, esvaziando, sendo simplificadas, enquanto outras, antes ligadas a áreas como a informática, ganham relevância e passam a fazer parte das ferramentas intelectuais que o jornalista é obrigado a dominar. O resultado é um amplo processo de desqualificação e re-qualificação, em detrimento do instrumental crítico, anteriormente vinculado à formação desses profissionais (BOLANO, 2006). ${ }^{3}$

A não limitação de espaços para ocupar com conteúdos e de horários para o fechamento de edições (o deadline convencional) ampliam a flexibilidade do tempo de trabalho do jornalista. Mesmo não havendo, em princípio, limites de espaço nas plataformas digitais, permanece a exigência de recursos necessários para garantir o volume e a qualidade do serviço, inclusive no que se refere ao aperfeiçoamento da convergência e das relações de interação com o consumidor. Além do mais, há horários específicos de maior interesse em disponibilizar conteúdos, variando quanto ao tipo e quantidade de material, ou hábitos de audiência, o que impede a inovação constante, nas atuais condições de desenvolvimento dos sistemas de jornalismo on-line.

\footnotetext{
3 À referida deterioração do instrumental crítico na formação dos jornalistas soma-se o fato de que o jornalismo digital traz novos problemas éticos, como os relativos à digitalização da imagem. "Ora, se bem que o retoque, a alteração, a supressão e a inclusão de elementos nas imagens fotojornalísticas sejam procedimentos relativamente comuns ao longo da história, o que é novo é o facto de a manipulação digital de fotografias ser fácil e de difícil ou virtualmente impossível detecção por um observador que não tenha visto o acontecimento fotograficamente representado. Por outro lado, embora a fotografia seja sempre uma forma de manipulação visual da realidade -recordemos a focagem ou o controle da profundidade de campo, da velocidade e da exposição- as tecnologias digitais exponenciaram esse fenómeno, pois transformam as imagens em impulsos electrónicos processáveis em computador. Tornou-se fácil, por exemplo, alterar, na imagem, as cores do cabelo, da roupa, dos olhos e da pele, alterar penteados, colocar frente a frente pessoas que nunca se viram, inserir pessoas e objectos em ambientes diferentes, criar imagens virtuais e combiná-las com imagens indiciáticas da realidade, etc". SOUSA, Jorge Pedro. A tolerância dos fotojornalistas portugueses à alteração digital de fotografias jornalísticas. Bocc - Biblioteca Online de Ciências da Comunicação, Covilhã, 1998. Disponível em: $<$ http://bocc.unisinos.br/pag/_texto.php?html2=sousa-jorge-pedro-qualidade-on-line.html $>$. Acesso em: 5 maio 2006.
} 
A maioria dos espaços jornalísticos digitais funciona muito mais como lugares para a disponibilização de informações já apuradas por outros meios, não raro do mesmo conglomerado empresarial. O trabalho desses novos veículos tem sido muito mais o de reaproveitamento de informações, que são apenas tratadas para sua utilização na internet.4 A reciclagem de textos passa a ser amplamente utilizada, o que, segundo Steinberger (2006), insere a informação jornalística em "uma cadeia de reconversões do valor de troca especialmente larga e veloz, em seu potencial de propagação". Esse fenômeno não foi inaugurado pela internet, como demonstra a atuação de emissoras de rádio interioranas, mas é expandido com a digitalização, pelo acesso aos materiais alheios, pela facilidade de fazer a transposição e pela escassez de profissionais para dar conta do preenchimento de todos os espaços com celeridade.

\section{Limitações e experiências}

Ao mesmo tempo, se a internet tornou-se um importante recurso de informação para o jornalismo em geral, inclusive pela possibilidade de acesso às fontes através do correio eletrônico, também resulta em conseqüências negativas qualitativas, não por alguma característica inata desta tecnologia, mas pela forma como é incorporada nas organizações midiáticas. Conforme Fernando Correia (2006, p. 116), com a internet "abriram-se também as portas para o 'esquecimento' da prática do contraditório e da configuração das fontes, assim como para a sedentarização profissional e o reforço do “jornalismo sentado"”.

A imprensa on-line apresenta um conjunto de mudanças na forma de organização empresarial, na sua relação com o mercado em geral e com as rotinas de trabalho. Algumas se destacam como inerentes ao momento atual das indústrias culturais, inseridas nesta fase do desenvolvimento capitalista. Um desses traços é a interatividade, que repercute no fazer

\footnotetext{
${ }^{4}$ Conforme Fabrizzia Bocaccio Cinel, as notícias do portal Globo.com constituem-se, basicamente, de uma transposição de conteúdo de outras mídias. CINEL, Fabrizzia Bocaccio. Portais de conteúdo jornalístico na internet sob o olhar da complexidade. 2002. Dissertação (Mestrado em Comunicação Social) - Programa de Pós-Graduação em Comunicação Social, Pontifícia Universidade Católica do Rio Grande do Sul, Porto Alegre.
} 
jornalístico, na participação do público (que é chamado a colaborar fornecendo conteúdos) e na possibilidade de rentabilização.5

Estudando o caso dos jornais on-line de Sergipe, Danielle Souza (2005) aponta, na prática cotidiana dessas empresas, o acúmulo de atividades por parte de um mesmo profissional, a exploração das possibilidades de sinergia entre diferentes meios e a predominância de estratégias de redução de custos, com a incorporação de estagiários. Estes, na prática, desenvolvem atividades de profissionais, funcionando como mão de obra barata, atuando em equipes cada vez mais reduzidas, onde todos têm que fazer de tudo um pouco, em algum momento. Para fugir dos regramentos do ofício, jornalistas e outros profissionais são agrupados sob a denominação genérica de produtores de conteúdo.

Se os custos de produção e difusão de notícias são reduzidos, por não haver gastos com compra de papel, estrutura industrial e distribuição em rede física, isso não corresponde a uma igualação de condições de competitividade, entre agentes de tamanhos e forças diversas. Nesse caso, o que ganha um papel preponderante são os arquivos, os profissionais renomados e as sinergias entre empresas de um mesmo conglomerado, que garantem conteúdos, jornalísticos inclusive, de fácil reconhecimento pelo público, o qual identifica um valor superior nesses materiais, motivo para consumi-los, em detrimento de outros.

Claro, no caso da internet, pela facilidade de navegação, no imenso mar de sítios disponíveis, a fidelização é relativa, podendo haver mudanças rápidas. No entanto, não há dúvida de que o retorno aos sítios de organizações com tradição midiática é mais constante, fator que deve ser analisado juntamente com o papel dos portais de busca e das relações entre os sítios (através de links). A própria marca (Globo, $\mathrm{CNN}$, etc.) vale como

\footnotetext{
${ }^{5}$ Como estratégia para otimizar o investimento publicitário dos anunciantes, o Google lançou um sistema em que os anúncios de vídeo do portal aparecem primeiramente como imagens estáticas, semelhantes a pequenas telas de TV. "Só quando o consumidor clica na tela o anúncio começa a ser exibido - em lugar de saltar da página sem aviso, como muitos comerciais online em vídeo fazem -, o que dá aos usuários o controle sobre o quanto desejam ver a publicidade". GOOGLE reinventa publicidade online com vídeos clicáveis. Telecom Online, São Paulo, 23 maio 2006. Disponível em: <http://www.telecomonline.com.br/>. Acesso em: 28 maio 2006.
} 
reputação, sendo a vantagem de precedência um sinal de distinção nesse ramo de negócios também.

É no âmbito dessa problemática que devem ser analisados os blogs, assim classificados por Raquel Recuero (2003):

Muitas vezes, os weblogs atuam como "diários virtuais", limitando-se a relatar as experiências pessoais do dia-a-dia de alguém. Em outras, são um apanhado de informações coletadas do ciberespaço, simplesmente "linkadas" e comentadas. Em outras tantas ainda, são tentativas de ficções. Em outras ainda, uma espécie de "revista eletrônica", mesclando informações variadas discutidas do ponto de vista crítico do autor. Muitas vezes ainda, os weblogs são uma mescla de todos esses estilos. Alguns weblogs são escritos através de várias mãos (embora todas devidamente identificadas). Outros são escritos apenas por um autor. Como se vê, trata-se de um fenômeno extremamente complexo. [...] Os weblogs, inicialmente identificados como uma nova tendência de diarismo na Internet, entretanto, têm representado uma violenta quebra de paradigmas no jornalismo e o mais importante: têm influenciado muito a maneira através da qual o jornalismo é praticado.

Conforme André Lemos (2002), os blogs oferecem um fluxo de comunicação alternativo ao das mídias de massa, de modo que "a Internet serve, assim, como uma forma de escoamento de discursos pessoais que foram há muito tempo inibidos pelos mass media". Não obstante, é sabido que os blogs têm sido cada vez mais incorporados pelas indústrias culturais, que abrem espaços para análises detalhadas e informações pormenorizadas de seus jornalistas, estabelecendo links a partir de seus portais, desta maneira agregando valor a eles. Jornais como o brasileiro O Globo, do conglomerado Organizações Roberto Marinho, contam com 32 blogs, onde alguns de seus colunistas tratam de suas especialidades, diferencial que é anunciado nas próprias páginas da publicação, o que atesta a captura desse recurso pela mídia hegemônica, como, aliás, tem ocorrido com toda a internet, a qual assimila cada vez mais a forma das indústrias culturais.

Os blogs independentes e espaços alternativos em geral têm, evidentemente, mais liberdade para ousar, inovando nos modos comunicativos e revelando-se menos influenciados pelos formatos tradicionais das indústrias culturais, até porque seus realizadores não vêm desta tradição. Por isso, tendem a ser acompanhados com atenção, 
pois funcionam como laboratórios, sendo suas práticas mais exitosas copiadas e adaptadas pelos meios hegemônicos no espaço dito virtual.

$\mathrm{Na}$ verdade, o uso das experiências alternativas como laboratório pelas grandes companhias é um traço comum na história das indústrias culturais. Nos setores de edição, especialmente o cinema e a edição fonográfica, a estrutura de mercado típica é caracterizada pela existência, ao lado de um número extremamente reduzido de majors, de um enorme contingente de pequenas empresas que assumem os riscos da inovação. $\mathrm{O}$ fenômeno é normalmente considerado, pela Economia Política da Comunicação (EPC), como conseqüência da dinâmica inovação-estandardização, decorrente da aleatoriedade, característica fundamental das indústrias culturais.6

Também é possível interpretá-lo, de forma semelhante ao que ocorre com os softwares livres, como produção de conhecimento ou informação realizada fora dos mecanismos convencionais do mercado de trabalho, apontando, é certo, para um modo de produção alternativo e, portanto, para a superação da exploração capitalista da força de trabalho intelectual, mas que serve, concretamente, nas condições atuais, para reduzir os custos salariais com os quais a empresa teria que arcar caso incorporasse aquela produção alternativa, subsumindo realmente o trabalho intelectual em questão.

Fica clara por um lado, a contradição, inerente ao desenvolvimento capitalista, entre o avanço das forças produtivas, com seu potencial liberador, e a manutenção, em essência, das relações de produção alienadas. Assim, nos espaços alternativos do jornalismo on-line, ao maior controle dos processos produtivos por parte do jornalista, que lhe garante maior liberdade para criar, corresponde carga superior de trabalho, tendo que dominar mecanismos como programação básica para construção de páginas web e produção digital de áudio e vídeo, características crescentemente exigidas pelos grandes portais.

Foi desencadeado tempo de enriquecimento e intensificação da exploração, exercida sobre o trabalho cultural, comunicacional, informacional, criativo, intelectual. Ampliam-se as potências do Homem e, progressivamente, reduzem-se os poderes dos

\footnotetext{
${ }^{6}$ Ver, por exemplo, BEAUD, Paul; FLICHY, Patrice; SAUVAGE, Monique. Geomètre contre saltimbanque: la prédominance de la programmation dans la télévision française. In: SOCIOLOGIE de la Télévision. France. Paris: Cnet, 1991.
} 
homens, submetendo-os mais ainda, em todos os níveis da sociabilidade, às imposições do sistema de dominação do capital. Isto tem a ver, por outro lado, com a característica do atual desenvolvimento das redes, que articula lógicas mercantis e não mercantis, para reduzir custos salariais, o que se traduz em formas renovadas de acumulação primitiva do conhecimento.

\section{Classificações e periodizações}

Os estudos de jornalismo fazem periodizações específicas. Cita-se a de Pavlik (2001), que fala em três fases: "na primeira, dominam os sítios que publicam o material editorial produzido, em primeira mão, para as edições em outros meios" ("modelo-mãe"); na segunda, os jornalistas usam o hyperlink para ampliar a chamada interatividade e criam conteúdos originais, mobilizando inclusive a criatividade do público. Segundo se depreende da descrição que faz Luciana Mielniczuk (2003, p. 46), o jornalismo online está entrando em uma nova fase, caracterizada pela "produção de conteúdos noticiosos originais desenvolvidos especificamente para a web, como o reconhecimento desta como novo meio de comunicação".

Interessante, mas não vale como periodização. Qual a lógica dessa seqüência de fases? $\mathrm{Na}$ verdade, vive-se um momento único de construção de algo em nível global na área do jornalismo. O quê? A definição da terceira fase aponta para a idéia de constituição de uma nova trajetória tecnológica, uma indústria cultural nova, em concorrência com as anteriores, mas todos sabem que se trata de algo muito mais complexo.

Não se pode, evidentemente, falar em gerações, para um arco de tempo tão curto. Afonso da Silva Júnior (2006) destaca, ao contrário, corretamente, a unidade, representada pela grande influência da forma jornal impresso no jornalismo da internet, o que é justificável, pela história dessa mídia e pelo fato de que os principais espaços informativos na web foram implantados por corporações que já atuavam na mídia tradicional: "se dentro do ambiente da Internet, temos a progressão [...], de estágios da criação, adaptação e gestão de conteúdos, vemos que em boa parte a metáfora do jornal impresso persiste enquanto sistema organizacional das informações baseadas em meio eletrônico". 
Não obstante, de forma progressiva começam a surgir formas alternativas, efetivamente próprias da internet, de disponibilizar conteúdos jornalísticos e de buscar a interação do público, um dos grandes diferenciais da web, cujas possibilidades de exploração devem crescer ao longo da expansão tecnológica e do conhecimento propiciado pelo uso da rede. Pondera-se, ainda, que a construção paulatina de sua própria forma organizativa é característica do processo midiático, recordando-se que a TV também copiou o rádio (inclusive no jornalismo) nos seus primeiros anos, até ter suas lógicas firmadas.

No âmbito ainda das classificações que circulam nos estudos de jornalismo, Mark Deuze (2004, p. 164), por exemplo, apresenta uma que tem por base como se processam a interatividade e o conteúdo, classificando o jornalismo on-line em: sites noticiosos de referência, sites de índice e categoria, sites de comentários e meta-sites, sites de partilha e de discussão. Os primeiros são os sítios noticiosos das indústrias culturais estabelecidas, como CNN e Warner. Os segundos são aqueles em que "os jornalistas on-line oferecem links aprofundados para outros sites na World Wide Web, os quais são algumas vezes categorizados e até anotados por equipas editoriais", como Yahoo e Paperboy (Deuze, 2004, p. 166). Na terceira categoria estão os sítios relativos a jornalismo e mídia em geral, a exemplo do Mediachannel e do Observatório da Imprensa. Já os sites de partilha e de discussão trabalham essencialmente para o intercâmbio de idéias e relatos, como os centros de mídia independente. Deuze enquadra os weblogs como sites temáticos ou de comentários (Deuze, 2004, p. 166).

Pode-se sugerir aqui novos instrumentos para a construção de taxonomias e periodização, na perspectiva da EPC defendida e da análise da dinâmica concorrencial dos mercados culturais. Primeiro, lista-se tipos de produtos encontrados na rede, que utilizam o jornalismo:

+ Versão de periódicos impressos: está na origem do webjornalismo, reproduzindo o material jornalístico do produto vendido a assinantes e compradores avulsos, como os sítios do Jornal do Brasil (o primeiro a lançar sua versão online no país, em 1995) e do Washington Post. 
+ Versão de produtos telejornalísticos: disponibiliza programas jornalísticos de televisão, através do material em vídeo. Pode ser complementada com textos escritos originalmente para o próprio produto televisivo. A Globo e a $\mathrm{CNN}$, dentre outros canais televisivos, disponibilizam alguns produtos jornalísticos na internet.

+ Versão de produtos radiojornalísticos: oferece programas jornalísticos de rádio, em áudio ou texto escrito original. É o caso dos sítios das rádios CBN e Band News, cujas programações são eminentemente jornalísticas.

+ Jornais eletrônicos: trabalham com atualizações constantes, trazendo sempre as notícias mais recentes. Pode ser uma versão atualizada de um jornal existente como edição impressa, mas na maioria das vezes trata-se de um produto específico para internet, como os mantidos pelos grandes provedores, a exemplo do Terra. Deu-se em 1996 o lançamento do primeiro jornal em tempo real em língua portuguesa da América Latina, o Brasil Online, do Universo Online (Uol), com informações de agências noticiosas e próprias.

+ Conteúdos jornalísticos de sítios e portais em geral: a maioria dos espaços na internet dispõe informações jornalísticas, de sua área de atuação (um sindicato, por exemplo) ou generalistas, produzidas por equipes próprias ou captadas de páginas de outras organizações, através de mecanismos de captura.

+ Blogs: são como blocos de notas sobre um tema específico ou diversos. Aqui, analisa-se sua concepção jornalística, mas os weblogs podem ter outros conteúdos, como o diário íntimo, que está na sua origem.

Outra classificação oportuna é aquela ligada às quatro características do jornalismo online, reconhecidas por Deuze e Bardoel (2001), interatividade, personalização/customização de conteúdo, hipertextualidade e multimedialidade, às quais Palacios (2003, p. 15-36) acrescenta duas, memória e instantaneidade de acesso/atualização contínua.Estas definições merecem uma ampliação em outra oportunidade.

\section{Considerações finais}

Mas o fundamental é que não se pode falar em uma trajetória do webjornalismo separada da trajetória da internet, esta ainda em fase extremamente jovem, mas na qual o 
problema do conteúdo se coloca já como crucial. O webjornalismo é parte das possibilidades de solução para esse problema atual da economia política da internet. Um vetor surgido na confluência entre diferentes trajetórias tecnológicas: da imprensa, do radio, da televisão, do acesso a bancos de dados, das diferentes formas de comunicação interativa, todas remetendo a uma história concreta, que tem na digitalização um momento fundamental de ruptura.

A Economia Política da Comunicação oferece essa perspectiva de conjunto da Indústria Cultural e das indústrias culturais particulares nos marcos do capitalismo monopolista e na transição atual do sistema. No concernente a este tema, a idéia de lógicas sociais tem já uma longa tradição,7 no interior da qual vêm sendo feitos estudos sobre o jornalismo digital. 8

No agregado, há já um conjunto de elementos que, apoiados no referencial teórico aqui defendido, e articulado a desenvolvimentos anteriores, expostos em outros trabalhos, permitirão a construção de um rico quadro de análise para o debate não apenas do jornalismo online, mas de outros objetos ligados à digitalização geral do mundo, atualmente em curso, vinculada às transformações do sistema no final do século XX e início do XXI. Propôs-se, em outra ocasião, que, para a articulação geral desse quadro analítico, é importante considerar a convergência e as lógicas sociais por camadas:

Num nível mais geral, encontra-se a classificação tradicional editorial/onda/imprensa. Logo abaixo, podemos definir os setores da TV segmentada, radio on line, ou imprensa on line, operadores, na prática, da convergência. Todos estes apresentam uma semelhança com a onda: não oferecem um bem individualizado, mas um conjunto de elementos que podemos classificar, em terceiro lugar, como partes de uma programação, paginação ou algo equivalente (BOLAÑO, 2006).

\footnotetext{
7 Ver, entre outros, MIÈGE, Bernard; PAJON, Patrick; SALAÜN, Jean-Michel. L'industrialisation de l'audiovisuel. Paris: Res. Babel, 1986; BOLAÑO, César Ricardo. Indústria cultural, informação e capitalismo. São Paulo: Hucitec, 2000.

${ }^{8}$ Notadamente ALBORNOZ, Luis. Los diarios online de información general: el caso de los grandes periódicos en español. 2005. Tese (Doutorado em Comunicación Audiovisual y Publicidad) - Facultad de Ciencias de la Información, Universidad Complutense de Madrid, Madri.
} 
Assim, tem-se também um método que garante a coerência do modelo, no interior do qual devem ser pensadas as lógicas sociais, as trajetórias tecnológicas, os ciclos de vida dos produtos culturais e o que é aqui chamado de vetores da convergência. Uma descrição mais detalhada da dinâmica do modelo extrapola os limites deste artigo, ficando para futuras abordagens.

\section{Referências}

ALBORNOZ, Luis. Los diarios online de información general: el caso de los grandes periódicos en español. 2005. Tese (Doutorado em Comunicación Audiovisual y Publicidad) - Facultad de Ciencias de la Información, Universidad Complutense de Madrid, Madri.

BARDOEL, Jo; DEUZE, Mark. Network Journalism: converging competences of old and new media professionals. Disponível em: <http://home.pscw.nl/deuze/pub/9.htm>. Acesso em: 28 jun. 2001.

BEAUD, Paul; FLICHY, Patrice; SAUVAGE, Monique. Geomètre contre saltimbanque: la prédominance de la programmation dans la télévision française. In: SOCIOLOGIE de la Télévision. France. Paris: Cnet, 1991.

BOLAÑO, César Ricardo. Indústria cultural, informação e capitalismo. São Paulo: Hucitec, 2000.

Jornalismo Online: reflexões a partir da Economia Política da Comunicação. Verso e Reverso, São Leopoldo, n. 43, jan.-maio 2006. Disponível em: $<$ http:/ $/$ www.versoereverso.unisinos.br/index.php?e $=7 \& s=9 \& a=60>$. Acesso em: 20 maio 2006.

BRITTOS, Valério. Políticas de comunicação, videodifusão e democracia no Brasil. São Leopoldo: Unisinos, 2006. Mimeografado.

CINEL, Fabrizzia Bocaccio. Portais de conteúdo jornalístico na internet sob o olhar da complexidade. 2002. Dissertação (Mestrado em Comunicação Social) - Programa de Pós-Graduação em Comunicação Social, Pontifícia Universidade Católica do Rio Grande do Sul, Porto Alegre.

CORREIA, Fernando. Jornalismo, grupos económicos e democracia. Lisboa: Caminho, 2006.

DEUZE, Mark. A internet e os seus jornalismos: teoria, pesquisa e estratégia da produção de notícias on-line. In: OLIVEIRA, José Manuel Paquete de; CARDOSO, Gustavo Leitão; BARREIROS, José Jorge. Comunicação, cultura e tecnologias de informação. Lisboa: Quimera, 2004. p. 161-189.

GOOGLE reinventa publicidade online com vídeos clicáveis. Telecom Online, São Paulo, 23 maio 2006. Disponível em: <http://www.telecomonline.com.br/>. Acesso em: 28 maio 2006. 
LEMOS, André L. M. A arte da vida: diários pessoais e webcams na internet. In: ENCONTRO NACIONAL DA ASSOCIAÇÃO NACIONAL DOS PROGRAMAS DE PÓSGRADUAÇÃO EM COMUNICAÇÃO, 10., 2002, Rio de Janeiro. Anais ... Belo Horizonte: Compós, 2002. 1 CD.

MIÈGE, Bernard; PAJON, Patrick; SALAÜN, Jean-Michel. L'industrialisation de l'audiovisuel. Paris: Res. Babel, 1986.

MIELNICZUK, Luciana. Sistematizando alguns conhecimentos sobre o jornalismo na web. In: MACHADO, Elias; PALACIOS, Marcos. Modelos de jornalismo digital. Salvador: Calandra, 2003. p. 37-54.

PALACIOS, Marcos. Ruptura, continuidade e potencialização no jornalismo on-line: o lugar da memória. In MACHADO, Elias; PALACIOS, Marcos. Modelos de jornalismo digital. Salvador: Calandra, 2003. p. 15-36.

PAVLIK, John. Journalism and new media. New York: Columbia UP, 2001.

RECUERO, Raquel da Cunha. Warblogs: os blogs, a Guerra do Iraque e o jornalismo online. Bocc - Biblioteca Online de Ciências da Comunicação, Covilhã, 2003. Disponível em: <http://bocc.unisinos.br/pag/recuero-raquel-war-blogs.pdf >. Acesso em: 3 maio 2006.

SALAÜN, Jean Michel. A qui appartient la télévision? Paris: Res-Babel, 1989.

SILVA JÚNIOR, José Afonso da. A relação das interfaces enquanto mediadoras de conteúdo do jornalismo contemporâneo: agências de notícias como estudo de caso. In: ENCONTRO NACIONAL DA ASSOCIAÇÃO NACIONAL DOS PROGRAMAS DE PÓSGRADUAÇÃO EM COMUNICAÇÃO, 11., 2002, Rio de Janeiro. Anais do GT Estudos de Jornalismo ... Porto Alegre: UFRGS, 2005. Disponível em: $<$ http://www.ufrgs.br/gtjornalismocompos/doc2002/silva_jr2002.doc>. Acesso em: 25 maio 2006.

SOUSA, Jorge Pedro. A tolerância dos fotojornalistas portugueses à alteração digital de fotografias jornalísticas. Bocc - Biblioteca Online de Ciências da Comunicação, Covilhã, 1998. Disponível em: <http://bocc.unisinos.br/pag/_texto.php?html2=sousa-jorgepedro-qualidade-on-line.html>. Acesso em: 5 maio 2006.

SOUZA, Danielle A. A internet como suporte jornalístico em Aracaju: adaptação dos jornais impressos à nova realidade tecnológica e econômica da mídia. 2005. Trabalho de Conclusão de Curso (Graduação em Comunicação Social - Jornalismo) - Centro de Artes, Universidade Federal de Sergipe, Aracaju.

STEINBERGER, Margarethe Born. El periodista como consumidor de información en la economía de las representaciónes digitales. Eptic Online - Revista de Economía Política de las Tecnologías de la Información y Comunicación, Aracaju, v. 8, n. 2, mayoago. 2006. Disponível em: <www.eptic.com.br>. Acesso em: 25 maio 2006. 